\title{
Convergence Analysis for a System of Generalized Equilibrium Problems and a Countable Family of Strict Pseudocontractions
}

\author{
Prasit Cholamjiak $^{\mathbf{1}}$ and Suthep Suantai ${ }^{1,2}$ \\ ${ }^{1}$ Department of Mathematics, Faculty of Science, Chiang Mai University, Chiang Mai 50200, Thailand \\ ${ }^{2}$ Centre of Excellence in Mathematics, CHE, Si Ayutthaya Road, Bangkok 10400, Thailand
}

Correspondence should be addressed to Suthep Suantai, scmti005@chiangmai.ac.th

Received 18 October 2010; Accepted 27 December 2010

Academic Editor: Jen Chih Yao

Copyright (C) 2011 P. Cholamjiak and S. Suantai. This is an open access article distributed under the Creative Commons Attribution License, which permits unrestricted use, distribution, and reproduction in any medium, provided the original work is properly cited.

We introduce a new iterative algorithm for a system of generalized equilibrium problems and a countable family of strict pseudocontractions in Hilbert spaces. We then prove that the sequence generated by the proposed algorithm converges strongly to a common element in the solutions set of a system of generalized equilibrium problems and the common fixed points set of an infinitely countable family of strict pseudocontractions.

\section{Introduction}

Let $H$ be a real Hilbert space with the inner product $\langle\cdot, \cdot\rangle$ and inducted norm $\|\cdot\|$. Let $C$ be a nonempty, closed, and convex subset of $H$. Let $\left\{f_{k}\right\}_{k \in \Lambda}: C \times C \rightarrow \mathbb{R}$ be a family of bifunctions, and let $\left\{A_{k}\right\}_{k \in \Lambda}: C \rightarrow H$ be a family of nonlinear mappings, where $\Lambda$ is an arbitrary index set. The system of generalized equilibrium problems is to find $\widehat{x} \in C$ such that

$$
f_{k}(\widehat{x}, y)+\left\langle A_{k} \widehat{x}, y-\widehat{x}\right\rangle \geq 0, \quad \forall y \in C, k \in \Lambda \text {. }
$$

If $\Lambda$ is a singleton, then (1.1) reduces to find $\widehat{x} \in C$ such that

$$
f(\widehat{x}, y)+\langle A \widehat{x}, y-\widehat{x}\rangle \geq 0, \quad \forall y \in C .
$$

The solutions set of (1.2) is denoted by $\operatorname{GEP}(f, A)$. If $f \equiv 0$, then the solutions set of (1.2) is denoted by $\operatorname{VI}(C, A)$, and if $A \equiv 0$, then the solutions set of $(1.2)$ is denoted by $\operatorname{EP}(f)$. 
The problem (1.2) is very general in the sense that it includes, as special cases, optimization problems, variational inequalities, minimax problems, and the Nash equilibrium problem in noncooperative games; see also [1,2]. Some methods have been constructed to solve the system of equilibrium problems (see, e.g., [3-7]). Recall that a mapping $A: C \rightarrow H$ is said to be

(1) monotone if

$$
\langle A x-A y, x-y\rangle \geq 0, \quad \forall x, y \in C
$$

(2) $\alpha$-inverse-strongly monotone if there exists a constant $\alpha>0$ such that

$$
\langle A x-A y, x-y\rangle \geq \alpha\|A x-A y\|^{2}, \quad \forall x, y \in C .
$$

It is easy to see that if $A$ is $\alpha$-inverse-strongly monotone, then $A$ is monotone and $1 / \alpha$-Lipschitz. conditions:

For solving the equilibrium problem, let us assume that $f$ satisfies the following

(A1) $f(x, x)=0$ for all $x \in C$,

(A2) $f$ is monotone, that is, $f(x, y)+f(y, x) \leq 0$ for all $x, y \in C$,

(A3) for each $x, y, z \in C, \lim _{t \rightarrow 0} f(t z+(1-t) x, y) \leq f(x, y)$,

(A4) for each $x \in C, y \mapsto f(x, y)$ is convex and lower semicontinuous.

Throughout this paper, we denote the fixed points set of a nonlinear mapping $T: C \rightarrow C$ by $F(T)=\{x \in C: T x=x\}$. Recall that $T$ is said to be a $\kappa$-strict pseudocontraction if there exists a constant $0 \leq \kappa<1$ such that

$$
\|T x-T y\|^{2} \leq\|x-y\|^{2}+\kappa\|(I-T) x-(I-T) y\|^{2} .
$$

It is well known that (1.5) is equivalent to

$$
\langle T x-T y, x-y\rangle \leq\|x-y\|^{2}-\frac{1-\kappa}{2}\|(I-T) x-(I-T) y\|^{2} .
$$

It is worth mentioning that the class of strict pseudocontractions includes properly the class of nonexpansive mappings. It is also known that every $\mathcal{\kappa}$-strict pseudocontraction is $((1+\kappa) /(1-\kappa))$-Lipschitz; see [8].

In 1953, Mann [9] introduced the iteration as follows: a sequence $\left\{x_{n}\right\}$ defined by $x_{0} \in C$ and

$$
x_{n+1}=\alpha_{n} x_{n}+\left(1-\alpha_{n}\right) S x_{n}, \quad n \geq 0,
$$

where $\left\{\alpha_{n}\right\}_{n=0}^{\infty} \subset[0,1]$. If $S$ is a nonexpansive mapping with a fixed point and the control sequence $\left\{\alpha_{n}\right\}_{n=0}^{\infty}$ is chosen so that $\sum_{n=0}^{\infty} \alpha_{n}\left(1-\alpha_{n}\right)=\infty$, then the sequence $\left\{x_{n}\right\}$ defined 
by (1.7) converges weakly to a fixed point of $S$ (this is also valid in a uniformly convex Banach space with the Fréchet differentiable norm [10]).

In 1967, Browder and Petryshyn [11] introduced the class of strict pseudocontractions and proved existence and weak convergence theorems in a real Hilbert setting by using Mann iterative algorithm (1.7) with a constant sequence $\alpha_{n}=\alpha$ for all $n \geq 0$. Recently, Marino and $\mathrm{Xu}$ [8] and Zhou [12] extended the results of Browder and Petryshyn [11] to Mann's iteration process (1.7). Since 1967, the construction of fixed points for pseudocontractions via the iterative process has been extensively investigated by many authors (see, e.g., [13-22]).

Let $C$ be a nonempty, closed, and convex subset of a real Hilbert space $H$. Let $S: C \rightarrow C$ be a nonexpansive mapping, $f: C \times C \rightarrow \mathbb{R}$ a bifunction, and let $A: C \rightarrow H$ be an inverse-strongly monotone mapping.

In 2008, Moudafi [23] introduced an iterative method for approximating a common element of the fixed points set of a nonexpansive mapping $S$ and the solutions set of a generalized equilibrium problem $\operatorname{GEP}(f, \mathrm{~A})$ as follows: a sequence $\left\{x_{n}\right\}$ defined by $x_{0} \in C$ and

$$
\begin{gathered}
f\left(y_{n}, y\right)+\left\langle A x_{n}, y-y_{n}\right\rangle+\frac{1}{r_{n}}\left\langle y-y_{n}, y_{n}-x_{n}\right\rangle \geq 0, \quad \forall y \in C, \\
x_{n+1}=\alpha_{n} x_{n}+\left(1-\alpha_{n}\right) S y_{n}, \quad n \geq 1,
\end{gathered}
$$

where $\left\{\alpha_{n}\right\}_{n=0}^{\infty} \subset(0,1)$ and $\left\{r_{n}\right\}_{n=0}^{\infty} \subset(0, \infty)$. He proved that the sequence $\left\{x_{n}\right\}$ generated by (1.8) converges weakly to an element in $\operatorname{GEP}(f, A) \cap F(S)$ under suitable conditions.

Due to the weak convergence, recently, S. Takahashi and W. Takahashi [24] introduced another modification iterative method of (1.8) for finding a common element of the fixed points set of a nonexpansive mapping and the solutions set of a generalized equilibrium problem in the framework of a real Hilbert space. To be more precise, they proved the following theorem.

Theorem 1.1 (see [24]). Let $C$ be a closed convex subset of a real Hilbert space $H$, and let $f: C \times C \rightarrow \mathbb{R}$ be a bifunction satisfying (A1)-(A4). Let $A$ be an $\alpha$-inverse-strongly monotone mapping of $C$ into $H$, and let $S$ be a nonexpansive mapping of $C$ into itself such that $F(S) \cap$ $\operatorname{GEP}(f, A) \neq \emptyset$. Let $u \in C$ and $x_{1} \in C$, and let $\left\{y_{n}\right\} \subset C$ and $\left\{x_{n}\right\} \subset C$ be sequences generated by

$$
\begin{gathered}
f\left(y_{n}, y\right)+\left\langle A x_{n}, y-y_{n}\right\rangle+\frac{1}{r_{n}}\left\langle y-y_{n}, y_{n}-x_{n}\right\rangle \geq 0, \quad \forall y \in C, \\
x_{n+1}=\beta_{n} x_{n}+\left(1-\beta_{n}\right) S\left[\alpha_{n} u+\left(1-\alpha_{n}\right) y_{n}\right], \quad n \geq 1,
\end{gathered}
$$

where $\left\{\alpha_{n}\right\}_{n=1}^{\infty} \subset[0,1],\left\{\beta_{n}\right\}_{n=1}^{\infty} \subset[0,1]$ and $\left\{r_{n}\right\}_{n=1}^{\infty} \subset[0,2 \alpha]$ satisfy

(i) $\lim _{n \rightarrow \infty} \alpha_{n}=0$ and $\sum_{n=1}^{\infty} \alpha_{n}=\infty$,

(ii) $0<c \leq \beta_{n} \leq d<1$,

(iii) $0<a \leq r_{n} \leq b<2 \alpha$,

(iv) $\lim _{n \rightarrow \infty}\left(r_{n}-r_{n+1}\right)=0$.

Then, $\left\{x_{n}\right\}$ converges strongly to $z=P_{F(S) \cap \operatorname{GEP}(f, A)} u$. 
Recently, Yao et al. [25] introduced a new modified Mann iterative algorithm which is different from those in the literature for a nonexpansive mapping in a real Hilbert space. To be more precise, they proved the following theorem.

Theorem 1.2 (see [25]). Let $C$ be a nonempty, closed, and convex subset of a real Hilbert space $H$. Let $S: C \rightarrow C$ be a nonexpansive mapping such that $F(S) \neq \emptyset$. Let $\left\{\alpha_{n}\right\}_{n=0}^{\infty}$, and let $\left\{\beta_{n}\right\}_{n=0}^{\infty}$ be two real sequences in $(0,1)$. For given $x_{0} \in C$ arbitrarily, let the sequence $\left\{x_{n}\right\}, n \geq 0$, be generated iteratively by

$$
\begin{gathered}
y_{n}=P_{C}\left[\left(1-\alpha_{n}\right) x_{n}\right], \\
x_{n+1}=\left(1-\beta_{n}\right) x_{n}+\beta_{n} S y_{n} .
\end{gathered}
$$

Suppose that the following conditions are satisfied:

(i) $\lim _{n \rightarrow \infty} \alpha_{n}=0$ and $\sum_{n=0}^{\infty} \alpha_{n}=\infty$,

(ii) $0<\liminf _{n \rightarrow \infty} \beta_{n} \leq \lim \sup _{n \rightarrow \infty} \beta_{n}<1$,

then, the sequence $\left\{x_{n}\right\}$ generated by (1.10) strongly converges to a fixed point of $S$.

We know the following crucial lemmas concerning the equilibrium problem in Hilbert spaces.

Lemma 1.3 (see [1]). Let $C$ be a nonempty, closed, and convex subset of a real Hilbert space $H$, let $f$ be a bifunction from $C \times C$ to $\mathbb{R}$ satisfying $(A 1)-(A 4)$. Let $r>0$ and $x \in H$. Then, there exists $z \in C$ such that

$$
f(z, y)+\frac{1}{r}\langle y-z, z-x\rangle \geq 0, \quad \forall y \in C
$$

Lemma 1.4 (see [26]). Let $C$ be a nonempty, closed, and convex subset of a real Hilbert space $H$. Let $f$ be a bifunction from $C \times C$ to $\mathbb{R}$ satisfying (A1)-(A4). For $x \in H$ and $r>0$, define the mapping $T_{r}^{f}: H \rightarrow 2^{C}$ as follows:

$$
T_{r}^{f}(x)=\left\{z \in C: f(z, y)+\frac{1}{r}\langle y-z, z-x\rangle \geq 0, \forall y \in C\right\} .
$$

Then, the following statements hold:

(1) $T_{r}^{f}$ is single-valued,

(2) $T_{r}^{f}$ is firmly nonexpansive, that is, for any $x, y \in H$,

$$
\left\|T_{r}^{f} x-T_{r}^{f} y\right\|^{2} \leq\left\langle T_{r}^{f} x-T_{r}^{f} y, x-y\right\rangle,
$$

(3) $F\left(T_{r}^{f}\right)=\operatorname{EP}(f)$,

(4) $\mathrm{EP}(f)$ is closed and convex. 
Let $C$ be a nonempty, closed, and convex subset of a real Hilbert space $H$. Let $r_{k}>0$ for each $k \in\{1,2, \ldots, M\}$. Let $\left\{f_{k}\right\}_{k=1}^{M}: C \times C \rightarrow \mathbb{R}$ be a family of bifunctions, let $\left\{A_{k}\right\}_{k=1}^{M}$ : $C \rightarrow H$ be a family of $\alpha_{k}$-inverse-strongly monotone mappings, and let $\left\{T_{n}\right\}_{n=1}^{\infty}: C \rightarrow C$ be a countable family of $\kappa$-strict pseudocontractions. For each $k \in\{1,2, \ldots, M\}$, denote the mapping $T_{r_{k}}^{f_{k}, A_{k}}: C \rightarrow C$ by $T_{r_{k}}^{f_{k}, A_{k}}:=T_{r_{k}}^{f_{k}}\left(I-r_{k} A_{k}\right)$, where $T_{r_{k}}^{f_{k}}: H \rightarrow C$ is the mapping defined as in Lemma 1.4.

Motivated and inspired by Marino and Xu [8], Moudafi [23], S. Takahashi and W. Takahashi [24], and Yao et al. [25], we consider the following iteration: $x_{1} \in C$ and

$$
\begin{gathered}
y_{n}=P_{C}\left[\left(1-\alpha_{n}\right) x_{n}\right], \\
u_{n}=T_{r_{M}}^{f_{M}, A_{M}} T_{r_{M-1}}^{f_{M-1}, A_{M-1}} \cdots T_{r_{2}}^{f_{2}, A_{2}} T_{r_{1}}^{f_{1}, A_{1}} y_{n} \\
x_{n+1}=\beta_{n} x_{n}+\left(1-\beta_{n}\right)\left[\gamma u_{n}+(1-\gamma) T_{n} u_{n}\right], \quad n \geq 1,
\end{gathered}
$$

where $\left\{\alpha_{n}\right\}_{n=1}^{\infty} \subset(0,1),\left\{\beta_{n}\right\}_{n=1}^{\infty} \subset(0,1)$ and $\gamma \in(0,1)$.

In this paper, we first prove a path convergence result for a nonexpansive mapping and a system of generalized equilibrium problems. Then, we prove a strong convergence theorem of the iteration process (1.14) for a system of generalized equilibrium problems and a countable family of strict pseudocontractions in a real Hilbert space. Our results extend the main results obtained by Yao et al. [25] in several aspects.

\section{Preliminaries}

Let $C$ be a nonempty, closed, and convex subset of a real Hilbert space $H$. For each $x \in H$, there exists a unique nearest point in $C$, denoted by $P_{C} x$, such that $\left\|x-P_{C} x\right\|=\min _{y \in C}\|x-y\|$. $P_{C}$ is called the metric projection of $H$ onto $C$. It is also known that for $x \in H$ and $z \in C$, $z=P_{C} x$ is equivalent to $\langle x-z, y-z\rangle \leq 0$ for all $y \in C$. Furthermore,

$$
\left\|y-P_{C} x\right\|^{2}+\left\|x-P_{C} x\right\|^{2} \leq\|x-y\|^{2}
$$

for all $x \in H, y \in C$. In a real Hilbert space, we also know that

$$
\|\lambda x+(1-\lambda) y\|^{2}=\lambda\|x\|^{2}+(1-\lambda)\|y\|^{2}-\lambda(1-\lambda)\|x-y\|^{2}
$$

for all $x, y \in H$ and $\lambda \in[0,1]$.

In the sequel, we need the following lemmas.

Lemma 2.1 (see $[27,28]$ ). Let $E$ be a real uniformly convex Banach space, and let $C$ be a nonempty, closed, and convex subset of $E$, and let $S: C \rightarrow C$ be a nonexpansive mapping such that $F(S) \neq \emptyset$, then $I-S$ is demiclosed at zero.

Lemma 2.2 (see [29]). Let $\left\{x_{n}\right\}$ and $\left\{z_{n}\right\}$ be two sequences in a Banach space E such that

$$
x_{n+1}=\beta_{n} x_{n}+\left(1-\beta_{n}\right) z_{n}, \quad n \geq 1,
$$


where $\left\{\beta_{n}\right\}_{n=1}^{\infty}$ satisfies conditions: $0<\liminf _{n \rightarrow \infty} \beta_{n} \leq \lim \sup _{n \rightarrow \infty} \beta_{n}<1$. If $\lim \sup _{n \rightarrow \infty}\left(\| z_{n+1}-\right.$ $\left.z_{n}\|-\| x_{n+1}-x_{n} \|\right) \leq 0$, then $\left\|x_{n}-z_{n}\right\| \rightarrow 0$ as $n \rightarrow \infty$.

Lemma 2.3 (see [30]). Assume that $\left\{a_{n}\right\}_{n=1}^{\infty}$ is a sequence of nonnegative real numbers such that

$$
a_{n+1} \leq\left(1-\gamma_{n}\right) a_{n}+\gamma_{n} \delta_{n}, \quad n \geq 1
$$

where $\left\{\gamma_{n}\right\}_{n=1}^{\infty}$ is a sequence in $(0,1)$ and $\left\{\delta_{n}\right\}_{n=1}^{\infty}$ is a sequence in $\mathbb{R}$ such that

(a) $\sum_{n=1}^{\infty} \gamma_{n}=\infty$; (b) $\lim \sup _{n \rightarrow \infty} \delta_{n} \leq 0$ or $\sum_{n=1}^{\infty}\left|\gamma_{n} \delta_{n}\right|<\infty$.

Then, $\lim _{n \rightarrow \infty} a_{n}=0$.

Lemma 2.4 (see [31]). Let $C$ be a nonempty, closed, and convex subset of a real Hilbert space $H$. Let the mapping $A: C \rightarrow H$ be $\alpha$-inverse-strongly monotone, and let $r>0$ be a constant. Then, we have

$$
\|(I-r A) x-(I-r A) y\|^{2} \leq\|x-y\|^{2}+r(r-2 \alpha)\|A x-A y\|^{2},
$$

for all $x, y \in C$. In particular, if $0 \leq r \leq 2 \alpha$, then $I-r A$ is nonexpansive.

To deal with a family of mappings, the following conditions are introduced: let $C$ be a subset of a real Hilbert space $H$, and let $\left\{T_{n}\right\}_{n=1}^{\infty}$ be a family of mappings of $C$ such that $\bigcap_{n=1}^{\infty} F\left(T_{n}\right) \neq \emptyset$. Then, $\left\{T_{n}\right\}$ is said to satisfy the AKTT-condition [32] if for each bounded subset $B$ of $C$,

$$
\sum_{n=1}^{\infty} \sup \left\{\left\|T_{n+1} z-T_{n} z\right\|: z \in B\right\}<\infty
$$

Lemma 2.5 (see [32]). Let $C$ be a nonempty and closed subset of a Hilbert space $H$, and let $\left\{T_{n}\right\}$ be a family of mappings of $C$ into itself which satisfies the AKTT-condition. Then, for each $x \in C,\left\{T_{n} x\right\}$ converges strongly to a point in $C$. Moreover, let the mapping $T$ be defined by

$$
T x=\lim _{n \rightarrow \infty} T_{n} x, \quad \forall x \in C .
$$

Then, for each bounded subset $B$ of $C$,

$$
\limsup _{n \rightarrow \infty}\left\{\left\|T z-T_{n} z\right\|: z \in B\right\}=0 .
$$

The following results can be found in $[33,34]$.

Lemma 2.6 (see $[33,34]$ ). Let $C$ be a closed, and convex subset of a Hilbert space $H$. Suppose that $\left\{T_{n}\right\}_{n=1}^{\infty}$ is a family of $\kappa$-strictly pseudocontractive mappings from $C$ into $H$ with $\bigcap_{n=1}^{\infty} F\left(T_{n}\right) \neq \emptyset$ and $\left\{\mu_{n}\right\}_{n=1}^{\infty}$ is a real sequence in $(0,1)$ such that $\sum_{n=1}^{\infty} \mu_{n}=1$. Then, the following conclusions hold:

(1) $G:=\sum_{n=1}^{\infty} \mu_{n} T_{n}: C \rightarrow H$ is a $\mathcal{\kappa}$-strictly pseudocontractive mapping,

(2) $F(G)=\bigcap_{n=1}^{\infty} F\left(T_{n}\right)$. 
Lemma 2.7 (see [34]). Let $C$ be a closed and convex subset of a Hilbert space $H$. Suppose that $\left\{S_{i}\right\}_{i=1}^{\infty}$ is a countable family of $\kappa$-strictly pseudocontractive mappings of $C$ into itself with $\bigcap_{i=1}^{\infty} F\left(S_{i}\right) \neq \emptyset$. For each $n \in \mathbb{N}$, define $T_{n}: C \rightarrow C$ by

$$
T_{n} x=\sum_{i=1}^{n} \mu_{n}^{i} S_{i} x, \quad x \in C
$$

where $\left\{\mu_{n}^{i}\right\}$ is a family of nonnegative numbers satisfying

(i) $\sum_{i=1}^{n} \mu_{n}^{i}=1$ for all $n \in \mathbb{N}$,

(ii) $\mu^{i}:=\lim _{n \rightarrow \infty} \mu_{n}^{i}>0$ for all $i \in \mathbb{N}$,

(iii) $\sum_{n=1}^{\infty} \sum_{i=1}^{n}\left|\mu_{n+1}^{i}-\mu_{n}^{i}\right|<\infty$.

Then,

(1) Each $T_{n}$ is a $\kappa$-strictly pseudocontractive mapping.

(2) $\left\{T_{n}\right\}$ satisfies AKTT-condition.

(3) If $T: C \rightarrow C$ is defined by

$$
T x=\sum_{i=1}^{\infty} \mu^{i} S_{i} x, \quad x \in C
$$

$$
\text { then } T x=\lim _{n \rightarrow \infty} T_{n} x \text { and } F(T)=\bigcap_{n=1}^{\infty} F\left(T_{n}\right)=\bigcap_{i=1}^{\infty} F\left(S_{i}\right) .
$$

In the sequel, we will write $\left(\left\{T_{n}\right\}, T\right)$ satisfies the AKTT-condition if $\left\{T_{n}\right\}$ satisfies the AKTT-condition and $T$ is defined by Lemma 2.5 with $F(T)=\bigcap_{n=1}^{\infty} F\left(T_{n}\right)$.

\section{Path Convergence Results}

Let $C$ be a nonempty, closed, and convex subset of a real Hilbert space $H$. Let $S: C \rightarrow C$ be a nonexpansive mapping. Let $\left\{f_{k}\right\}_{k=1}^{M}: C \times C \rightarrow \mathbb{R}$ be a family of bifunctions, let $\left\{A_{k}\right\}_{k=1}^{M}$ : $C \rightarrow H$ be a family of $\alpha_{k}$-inverse-strongly monotone mappings, and let $r_{k} \in\left(0,2 \alpha_{k}\right)$. For each $k \in\{1,2, \ldots, M\}$, we denote the mapping $T_{r_{k}}^{f_{k}, A_{k}}: C \rightarrow C$ by

$$
T_{r_{k}}^{f_{k}, A_{k}}:=T_{r_{k}}^{f_{k}}\left(I-r_{k} A_{k}\right)
$$

where $T_{r_{k}}^{f_{k}}$ is the mapping defined as in Lemma 1.4. For each $t \in(0,1)$, we define the mapping $S_{t}: C \rightarrow C$ as follows:

$$
S_{t} x=S T_{r_{M}}^{f_{M}, A_{M}} T_{r_{M-1}}^{f_{M-1}, A_{M-1}} \cdots T_{r_{1}}^{f_{1}, A_{1}} P_{C}[(1-t) x], \quad \forall x \in C .
$$

By Lemmas 1.4(2) and 2.4, we know that $T_{r_{k}}^{f_{k}}$ and $I-r_{k} A_{k}$ are nonexpansive for each $k \in\{1,2, \ldots, M\}$. So, the mapping $T_{r_{k}}^{f_{k}, A_{k}}$ is also nonexpansive for each $k \in\{1,2, \ldots, M\}$. 
Moreover, we can check easily that $S_{t}$ is a contraction. Then, the Banach contraction principle ensures that there exists a unique fixed point $x_{t}$ of $S_{t}$ in $C$, that is,

$$
x_{t}=S T_{r_{M}}^{f_{M}, A_{M}} T_{r_{M-1}}^{f_{M-1}, A_{M-1}} \cdots T_{r_{1}}^{f_{1}, A_{1}} P_{C}\left[(1-t) x_{t}\right], \quad t \in(0,1) .
$$

Theorem 3.1. Let $C$ be a nonempty, closed, and convex subset of a real Hilbert space $H$. Let $S: C \rightarrow C$ be a nonexpansive mapping. Let $\left\{f_{k}\right\}_{k=1}^{M}: C \times C \rightarrow \mathbb{R}$ be a family of bifunctions, let $\left\{A_{k}\right\}_{k=1}^{M}: C \rightarrow H$ be a family of $\alpha_{k}$-inverse-strongly monotone mappings, and let $r_{k} \in$ $\left(0,2 \alpha_{k}\right)$. For each $k \in\{1,2, \ldots, M\}$, let the mapping $T_{r_{k}}^{f_{k}, A_{k}}$ be defined by (3.1). Assume that $F:=\left(\bigcap_{k=1}^{M} \operatorname{GEP}\left(f_{k}, A_{k}\right)\right) \cap\left(\bigcap_{n=1}^{\infty} F\left(T_{n}\right)\right) \neq \emptyset$. For each $t \in(0,1)$, let the net $\left\{x_{t}\right\}$ be generated by (3.3). Then, as $t \rightarrow 0$, the net $\left\{x_{t}\right\}$ converges strongly to an element in $F$.

Proof. First, we show that $\left\{x_{t}\right\}$ is bounded. For each $t \in(0,1)$, let $y_{t}=P_{C}\left[(1-t) x_{t}\right]$ and $u_{t}=T_{r_{M}}^{f_{M}, A_{M}} T_{r_{M-1}}^{f_{M-1}, A_{M-1}} \cdots T_{r_{1}}^{f_{1}, A_{1}} y_{t}$. From (3.3), we have for each $p \in F$ that

$$
\left\|x_{t}-p\right\|=\left\|S u_{t}-S p\right\| \leq\left\|u_{t}-p\right\| \leq\left\|y_{t}-p\right\| \leq(1-t)\left\|x_{t}-p\right\|+t\|p\| .
$$

It follows that

$$
\left\|x_{t}-p\right\| \leq\|p\| .
$$

Hence, $\left\{x_{t}\right\}$ is bounded and so are $\left\{y_{t}\right\}$ and $\left\{u_{t}\right\}$. Observe that

$$
\left\|y_{t}-x_{t}\right\| \leq t\left\|x_{t}\right\| \longrightarrow 0
$$

as $t \rightarrow 0$ since $\left\{x_{t}\right\}$ is bounded.

Next, we show that $\left\|u_{t}-x_{t}\right\| \rightarrow 0$ as $t \rightarrow 0$. Denote $\Theta^{k}=T_{r_{k}}^{f_{k}, A_{k}} T_{r_{k-1}}^{f_{k-1}, A_{k-1}} \cdots T_{r_{1}}^{f_{1}, A_{1}}$ for any $k \in\{1,2, \ldots, M\}$ and $\Theta^{0}=I$. We note that $u_{t}=\Theta^{M} y_{t}$ for each $t \in(0,1)$. From Lemma 2.4, we have for each $k \in\{1,2, \ldots, M\}$ and $p \in F$ that

$$
\begin{aligned}
\left\|\Theta^{k} y_{t}-p\right\|^{2} & =\left\|T_{r_{k}}^{f_{k}, A_{k}} \Theta^{k-1} y_{t}-T_{r_{k}}^{f_{k}, A_{k}} \Theta^{k-1} p\right\|^{2} \\
& =\left\|T_{r_{k}}^{f_{k}}\left(\Theta^{k-1} y_{t}-r_{k} A_{k} \Theta^{k-1} y_{t}\right)-T_{r_{k}}^{f_{k}}\left(\Theta^{k-1} p-r_{k} A_{k} \Theta^{k-1} p\right)\right\|^{2} \\
& \leq\left\|\left(\Theta^{k-1} y_{t}-r_{k} A_{k} \Theta^{k-1} y_{t}\right)-\left(\Theta^{k-1} p-r_{k} A_{k} \Theta^{k-1} p\right)\right\|^{2} \\
& \leq\left\|\Theta^{k-1} y_{t}-p\right\|^{2}+r_{k}\left(r_{k}-2 \alpha_{k}\right)\left\|A_{k} \Theta^{k-1} y_{t}-A_{k} p\right\|^{2} .
\end{aligned}
$$


It follows that

$$
\begin{aligned}
\left\|u_{t}-p\right\|^{2} & =\left\|\Theta^{M} y_{t}-p\right\|^{2} \\
& \leq\left\|y_{t}-p\right\|^{2}+\sum_{i=1}^{M} r_{i}\left(r_{i}-2 \alpha_{i}\right)\left\|A_{i} \Theta^{i-1} y_{t}-A_{i} p\right\|^{2} \\
& =\left\|P_{C}\left[(1-t) x_{t}\right]-p\right\|^{2}+\sum_{i=1}^{M} r_{i}\left(r_{i}-2 \alpha_{i}\right)\left\|A_{i} \Theta^{i-1} y_{t}-A_{i} p\right\|^{2} \\
& \leq\left(\left\|x_{t}-p\right\|+t\left\|x_{t}\right\|\right)^{2}+\sum_{i=1}^{M} r_{i}\left(r_{i}-2 \alpha_{i}\right)\left\|A_{i} \Theta^{i-1} y_{t}-A_{i} p\right\|^{2} \\
& \leq\left\|x_{t}-p\right\|^{2}+t M_{1}+\sum_{i=1}^{M} r_{i}\left(r_{i}-2 \alpha_{i}\right)\left\|A_{i} \Theta^{i-1} y_{t}-A_{i} p\right\|^{2},
\end{aligned}
$$

where $M_{1}=\sup _{0<t<1}\left\{2\left\|x_{t}-p\right\|\left\|x_{t}\right\|+t\left\|x_{t}\right\|^{2}\right\}$. So, we have

$$
\begin{aligned}
\left\|x_{t}-p\right\|^{2} & \leq\left\|u_{t}-p\right\|^{2} \\
& \leq\left\|x_{t}-p\right\|^{2}+t M_{1}+\sum_{i=1}^{M} r_{i}\left(r_{i}-2 \alpha_{i}\right)\left\|A_{i} \Theta^{i-1} y_{t}-A_{i} p\right\|^{2},
\end{aligned}
$$

which implies that

$$
\lim _{t \rightarrow 0}\left\|A_{k} \Theta^{k-1} y_{t}-A_{k} p\right\|=0
$$

for each $k \in\{1,2, \ldots, M\}$. Since $T_{r_{k}}^{f_{k}}$ is firmly nonexpansive for each $k \in\{1,2, \ldots, M\}$, we have for each $p \in F$ and $k \in\{1,2, \ldots, M\}$ that

$$
\begin{aligned}
\left\|\Theta^{k} y_{t}-p\right\|^{2} & =\left\|T_{r_{k}}^{f_{k}, A_{k}} \Theta^{k-1} y_{t}-T_{r_{k}}^{f_{k}, A_{k}} \Theta^{k-1} p\right\|^{2} \\
& =\left\|T_{r_{k}}^{f_{k}}\left(\Theta^{k-1} y_{t}-r_{k} A_{k} \Theta^{k-1} y_{t}\right)-T_{r_{k}}^{f_{k}}\left(\Theta^{k-1} p-r_{k} A_{k} \Theta^{k-1} p\right)\right\|^{2} \\
& \leq\left\langle\Theta^{k-1} y_{t}-r_{k} A_{k} \Theta^{k-1} y_{t}-\left(p-r_{k} A_{k} p\right), \Theta^{k} y_{t}-p\right\rangle \\
& =\frac{1}{2}\left(\left\|\Theta^{k-1} y_{t}-r_{k} A_{k} \Theta^{k-1} y_{t}-\left(p-r_{k} A_{k} p\right)\right\|^{2}+\left\|\Theta^{k} y_{t}-p\right\|^{2}\right. \\
& \left.\quad-\left\|\Theta^{k-1} y_{t}-r_{k} A_{k} \Theta^{k-1} y_{t}-\left(p-r_{k} A_{k} p\right)-\left(\Theta^{k} y_{t}-p\right)\right\|^{2}\right)
\end{aligned}
$$




$$
\begin{aligned}
& \leq \frac{1}{2}\left(\left\|\Theta^{k-1} y_{t}-p\right\|^{2}+\left\|\Theta^{k} y_{t}-p\right\|^{2}-\left\|\Theta^{k-1} y_{t}-\Theta^{k} y_{t}-r_{k}\left(A_{k} \Theta^{k-1} y_{t}-A_{k} p\right)\right\|^{2}\right) \\
& \leq \frac{1}{2}\left(\left\|\Theta^{k-1} y_{t}-p\right\|^{2}+\left\|\Theta^{k} y_{t}-p\right\|^{2}-\left\|\Theta^{k-1} y_{t}-\Theta^{k} y_{t}\right\|^{2}\right. \\
& \left.\quad+2 r_{k}\left\|\Theta^{k-1} y_{t}-\Theta^{k} y_{t}\right\|\left\|A_{k} \Theta^{k-1} y_{t}-A_{k} p\right\|\right) .
\end{aligned}
$$

This implies that

$$
\begin{aligned}
\left\|\Theta^{k} y_{t}-p\right\|^{2} \leq & \left\|\Theta^{k-1} y_{t}-p\right\|^{2}-\left\|\Theta^{k-1} y_{t}-\Theta^{k} y_{t}\right\|^{2} \\
& +2 r_{k}\left\|\Theta^{k-1} y_{t}-\Theta^{k} y_{t}\right\|\left\|A_{k} \Theta^{k-1} y_{t}-A_{k} p\right\| \\
\leq & \left\|\Theta^{k-1} y_{t}-p\right\|^{2}-\left\|\Theta^{k-1} y_{t}-\Theta^{k} y_{t}\right\|^{2}+M_{2}\left\|A_{k} \Theta^{k-1} y_{t}-A_{k} p\right\|,
\end{aligned}
$$

where $M_{2}=\max _{1 \leq k \leq M} \sup _{0<t<1}\left\{2 r_{k}\left\|\Theta^{k-1} y_{t}-\Theta^{k} y_{t}\right\|\right\}$. This shows that

$$
\begin{aligned}
\left\|u_{t}-p\right\|^{2} & =\left\|\Theta^{M} y_{t}-p\right\|^{2} \\
& \leq\left\|y_{t}-p\right\|^{2}-\sum_{i=1}^{M}\left\|\Theta^{i-1} y_{t}-\Theta^{i} y_{t}\right\|^{2}+M_{2} \sum_{i=1}^{M}\left\|A_{i} \Theta^{i-1} y_{t}-A_{i} p\right\| \\
& \leq\left\|x_{t}-p\right\|^{2}+t M_{1}-\sum_{i=1}^{M}\left\|\Theta^{i-1} y_{t}-\Theta^{i} y_{t}\right\|^{2}+M_{2} \sum_{i=1}^{M}\left\|A_{i} \Theta^{i-1} y_{t}-A_{i} p\right\| .
\end{aligned}
$$

Hence,

$$
\begin{aligned}
\left\|x_{t}-p\right\|^{2} & \leq\left\|u_{t}-p\right\|^{2} \\
& \leq\left\|x_{t}-p\right\|^{2}+t M_{1}-\sum_{i=1}^{M}\left\|\Theta^{i-1} y_{t}-\Theta^{i} y_{t}\right\|^{2}+M_{2} \sum_{i=1}^{M}\left\|A_{i} \Theta^{i-1} y_{t}-A_{i} p\right\| .
\end{aligned}
$$

From (3.10), we obtain

$$
\sum_{i=1}^{M}\left\|\Theta^{i-1} y_{t}-\Theta^{i} y_{t}\right\| \longrightarrow 0
$$

as $t \rightarrow 0$. So, we can conclude that

$$
\lim _{t \rightarrow 0}\left\|\Theta^{k-1} y_{t}-\Theta^{k} y_{t}\right\|=0
$$


for each $k \in\{1,2, \ldots, M\}$. Observing

$$
\begin{aligned}
\left\|u_{n}-y_{t}\right\| & =\left\|\Theta^{M} y_{t}-y_{t}\right\| \\
& \leq\left\|\Theta^{M} y_{t}-\Theta^{M-1} y_{t}\right\|+\left\|\Theta^{M-1} y_{t}-\Theta^{M-2} y_{t}\right\|+\cdots+\left\|\Theta^{1} y_{t}-y_{t}\right\|,
\end{aligned}
$$

it follows by (3.16) that

$$
\lim _{t \rightarrow 0}\left\|u_{t}-y_{t}\right\|=0
$$

From (3.6) and (3.18), we have

$$
\lim _{t \rightarrow 0}\left\|u_{t}-x_{t}\right\|=0
$$

Hence,

$$
\left\|x_{t}-S x_{t}\right\|=\left\|S u_{t}-S x_{t}\right\| \leq\left\|u_{t}-x_{t}\right\| \longrightarrow 0,
$$

as $t \rightarrow 0$.

Next, we show that $\left\{x_{t}\right\}$ is relatively norm compact as $t \rightarrow 0$. Let $\left\{t_{n}\right\} \subset(0,1)$ be a sequence such that $t_{n} \rightarrow 0$ as $n \rightarrow \infty$. Put $x_{n}:=x_{t_{n}}$. From (3.20), we obtain

$$
\lim _{n \rightarrow \infty}\left\|x_{n}-S x_{n}\right\|=0
$$

Since $\left\{x_{n}\right\}$ is bounded, without loss of generality, we may assume that $\left\{x_{n}\right\}$ converges weakly to $x^{*} \in C$. Applying Lemma 2.1 to (3.21), we can conclude that $x^{*} \in F(S)$.

Next, we show that $x^{*} \in \bigcap_{k=1}^{M} \operatorname{GEP}\left(f_{k}, A_{k}\right)$. Note that $\Theta^{k} y_{n}=T_{r_{k}}^{f_{k}, A_{k}} \Theta^{k-1} y_{n}=$ $T_{r_{k}}^{f_{k}}\left(\Theta^{k-1} y_{n}-r_{k} A_{k} \Theta^{k-1} y_{n}\right)$ for each $k \in\{1,2, \ldots, M\}$. Hence, for each $y \in C$ and $k \in$ $\{1,2, \ldots, M\}$, we obtain

$$
f_{k}\left(\Theta^{k} y_{n}, y\right)+\frac{1}{r_{k}}\left\langle y-\Theta^{k} y_{n}, \Theta^{k} y_{n}-\left(\Theta^{k-1} y_{n}-r_{k} A_{k} \Theta^{k-1} y_{n}\right)\right\rangle \geq 0
$$

From (A2), we have

$$
\frac{1}{r_{k}}\left\langle y-\Theta^{k} y_{n}, \Theta^{k} y_{n}-\left(\Theta^{k-1} y_{n}-r_{k} A_{k} \Theta^{k-1} y_{n}\right)\right\rangle \geq f_{k}\left(y, \Theta^{k} y_{n}\right), \quad \forall y \in C
$$

Therefore,

$$
\left\langle y-\Theta^{k} y_{n_{j}}, \frac{\Theta^{k} y_{n_{j}}-\Theta^{k-1} y_{n_{j}}}{r_{k}}+A_{k} \Theta^{k-1} y_{n_{j}}\right\rangle \geq f_{k}\left(y, \Theta^{k} y_{n_{j}}\right), \quad \forall y \in C .
$$


For each $t \in(0,1)$ and $y \in C$, put $z_{t}=t y+(1-t) x^{*}$. Then, we have $z_{t} \in C$. From (3.24), we get that

$$
\begin{aligned}
\left\langle z_{t}-\Theta^{k} y_{n_{j}}, A_{k} z_{t}\right\rangle \geq & \left\langle z_{t}-\Theta^{k} y_{n_{j}}, A_{k} z_{t}\right\rangle \\
& -\left\langle z_{t}-\Theta^{k} y_{n_{j}}, \frac{\Theta^{k} y_{n_{j}}-\Theta^{k-1} y_{n_{j}}}{r_{k}}+A_{k} \Theta^{k-1} y_{n_{j}}\right\rangle+f_{k}\left(z_{t}, \Theta^{k} y_{n_{j}}\right) \\
= & \left\langle z_{t}-\Theta^{k} y_{n_{j}}, A_{k} z_{t}-A_{k} \Theta^{k} y_{n_{j}}\right\rangle+\left\langle z_{t}-\Theta^{k} y_{n_{j}}, A_{k} \Theta^{k} y_{n_{j}}-A_{k} \Theta^{k-1} y_{n_{j}}\right\rangle \\
& -\left\langle z_{t}-\Theta^{k} y_{n_{j}}, \frac{\Theta^{k} y_{n_{j}}-\Theta^{k-1} y_{n_{j}}}{r_{k}}\right\rangle+f_{k}\left(z_{t}, \Theta^{k} y_{n_{j}}\right) .
\end{aligned}
$$

We note that $\left\|A_{k} \Theta^{k} y_{n_{j}}-A_{k} \Theta^{k-1} y_{n_{j}}\right\| \leq\left(1 / \alpha_{k}\right)\left\|\Theta^{k} y_{n_{j}}-\Theta^{k-1} y_{n_{j}}\right\| \rightarrow 0, \Theta^{k} y_{n_{j}} \rightarrow x^{*}$ as $j \rightarrow \infty$, and $\left\{A_{k}\right\}_{k=1}^{M}$ is a family of monotone mappings. It follows from (3.25) that

$$
\left\langle z_{t}-x^{*}, A_{k} z_{t}\right\rangle \geq f_{k}\left(z_{t}, x^{*}\right)
$$

So, by (A1), (A4) and (3.26), we have for each $y \in C$ and $k \in\{1,2, \ldots, M\}$ that

$$
\begin{aligned}
0 & =f_{k}\left(z_{t}, z_{t}\right) \leq t f_{k}\left(z_{t}, y\right)+(1-t) f_{k}\left(z_{t}, x^{*}\right) \\
& \leq t f_{k}\left(z_{t}, y\right)+(1-t)\left\langle z_{t}-x^{*}, A_{k} z_{t}\right\rangle \\
& =t f_{k}\left(z_{t}, y\right)+t(1-t)\left\langle y-x^{*}, A_{k} z_{t}\right\rangle .
\end{aligned}
$$

This implies that

$$
f_{k}\left(z_{t}, y\right)+(1-t)\left\langle y-x^{*}, A_{k} z_{t}\right\rangle \geq 0, \quad \forall y \in C
$$

Letting $t \rightarrow 0$ in (3.28), it follows from (A3) that

$$
f_{k}\left(x^{*}, y\right)+\left\langle y-x^{*}, A_{k} x^{*}\right\rangle \geq 0, \quad \forall y \in C
$$


Hence $x^{*} \in \bigcap_{k=1}^{M} \operatorname{GEP}\left(f_{k}, A_{k}\right)$; consequently, $x^{*} \in F$. Further, we see that

$$
\begin{aligned}
\left\|x_{t}-x^{*}\right\|^{2} & =\left\|S u_{t}-x^{*}\right\|^{2} \\
& \leq\left\|u_{t}-x^{*}\right\|^{2} \\
& \leq\left\|y_{t}-x^{*}\right\|^{2} \\
& \leq\left\|x_{t}-x^{*}-t x_{t}\right\|^{2} \\
& =\left\|x_{t}-x^{*}\right\|^{2}-2 t\left\langle x_{t}, x_{t}-x^{*}\right\rangle+t^{2}\left\|x_{t}\right\|^{2} \\
& =\left\|x_{t}-x^{*}\right\|^{2}-2 t\left\langle x_{t}-x^{*}, x_{t}-x^{*}\right\rangle-2 t\left\langle x^{*}, x_{t}-x^{*}\right\rangle+t^{2}\left\|x_{t}\right\|^{2} .
\end{aligned}
$$

So, we have

$$
\left\|x_{t}-x^{*}\right\|^{2} \leq\left\langle x^{*}, x^{*}-x_{t}\right\rangle+\frac{t}{2}\left\|x_{t}\right\|^{2}
$$

In particular,

$$
\left\|x_{n}-x^{*}\right\|^{2} \leq\left\langle x^{*}, x^{*}-x_{n}\right\rangle+\frac{t_{n}}{2}\left\|x_{n}\right\|^{2} .
$$

Since $x_{n} \rightarrow x^{*}$, we have $x_{n} \rightarrow x^{*}$ as $n \rightarrow \infty$. By using the same argument as in the proof of Theorem 3.1 of [25], we can show that $x_{t} \rightarrow x^{*} \in F$ as $t \rightarrow 0$. This completes the proof.

\section{Strong Convergence Results}

Theorem 4.1. Let $C$ be a nonempty, closed and convex subset of a real Hilbert space $H$. Let $\left\{f_{k}\right\}_{k=1}^{M}$ : $C \times C \rightarrow \mathbb{R}$ be a family of bifunctions, let $\left\{A_{k}\right\}_{k=1}^{M}: C \rightarrow H$ be a family of $\alpha_{k}$-inverse-strongly monotone mappings and let $\left\{T_{n}\right\}_{n=1}^{\infty}: C \rightarrow C$ be a countable family of $\mathcal{\kappa}$-strict pseudocontractions for some $0<\kappa<1$ such that $F:=\left(\bigcap_{k=1}^{M} \operatorname{GEP}\left(f_{k}, A_{k}\right)\right) \cap\left(\bigcap_{n=1}^{\infty} F\left(T_{n}\right)\right) \neq \emptyset$. Assume that $\left\{\alpha_{n}\right\}_{n=1}^{\infty} \subset(0,1)$, $\left\{\beta_{n}\right\}_{n=1}^{\infty} \subset(0,1), \gamma \in(\kappa, 1)$ and $r_{k} \in\left(0,2 \alpha_{k}\right)$ for each $k \in\{1,2, \ldots, M\}$ satisfy the following conditions:

(i) $\lim _{n \rightarrow \infty} \alpha_{n}=0$ and $\sum_{n=1}^{\infty} \alpha_{n}=\infty$,

(ii) $0<\liminf _{n \rightarrow \infty} \beta_{n} \leq \lim \sup _{n \rightarrow \infty} \beta_{n}<1$.

Suppose that $\left(\left\{T_{n}\right\}, T\right)$ satisfies the AKTT-condition. Then, $\left\{x_{n}\right\}$ generated by (1.14) converges strongly to an element in $F$.

Proof. For each $n \in \mathbb{N}$, define $S_{n}: C \rightarrow C$ by $S_{n} x=\gamma x+(1-\gamma) T_{n} x, x \in C$. Then, $F\left(S_{n}\right)=$ $F\left(T_{n}\right)=F(T)$, since $\gamma \in(0,1)$. Moreover, we know that $\left\{S_{n}\right\}$ satisfies the AKTT-condition, since $\left\{T_{n}\right\}$ satisfies the AKTT-condition. By Lemma 2.5, we can define the mapping $S: C \rightarrow$ $C$ by $S x=\lim _{n \rightarrow \infty} S_{n} x$ for $x \in C$. Hence, $S x=\gamma x+(1-\gamma) T x, x \in C$, since $T_{n} x \rightarrow T x$ for 
$x \in C$. Further, we know that $S_{n}$ is nonexpansive for each $n \in \mathbb{N}$. Indeed, for each $x, y \in C$ and $n \in \mathbb{N}$, we have

$$
\begin{aligned}
\left\|S_{n} x-S_{n} y\right\|^{2}= & \left\|\gamma x+(1-\gamma) T_{n} x-r y-(1-\gamma) T_{n} y\right\|^{2} \\
= & \left\|\gamma(x-y)+(1-\gamma)\left(T_{n} x-T_{n} y\right)\right\|^{2} \\
= & \gamma\|x-y\|^{2}+(1-\gamma)\left\|T_{n} x-T_{n} y\right\|^{2}-\gamma(1-\gamma)\left\|\left(I-T_{n}\right) x-\left(I-T_{n}\right) y\right\|^{2} \\
\leq & \gamma\|x-y\|^{2}+(1-\gamma)\|x-y\|^{2}+(1-\gamma) \kappa\left\|\left(I-T_{n}\right) x-\left(I-T_{n}\right) y\right\|^{2} \\
& -\gamma(1-\gamma)\left\|\left(I-T_{n}\right) x-\left(I-T_{n}\right) y\right\|^{2} \\
= & \|x-y\|^{2}+(1-\gamma)(\kappa-\gamma)\left\|\left(I-T_{n}\right) x-\left(I-T_{n}\right) y\right\|^{2} \\
\leq & \|x-y\|^{2} .
\end{aligned}
$$

Hence, $S_{n}$ is nonexpansive for each $n \in \mathbb{N}$ and so is $S$.

Next, we show that $\left\{x_{n}\right\}$ is bounded. Denote $\Theta^{k}=T_{r_{k}}^{f_{k}, A_{k}} T_{r_{k-1}}^{f_{k-1}, A_{k-1}} \cdots T_{r_{1}}^{f_{1}, A_{1}}$ for any $k \in\{1,2, \ldots, M\}$ and $\Theta^{0}=I$. We note that $u_{n}=\Theta^{M} y_{n}$. From (1.14), we have for each $p \in F$ that

$$
\begin{aligned}
\left\|x_{n+1}-p\right\| & =\left\|\beta_{n} x_{n}+\left(1-\beta_{n}\right) S_{n} u_{n}\right\| \\
& \leq \beta_{n}\left\|x_{n}-p\right\|+\left(1-\beta_{n}\right)\left\|S_{n} u_{n}-p\right\| \\
& \leq \beta_{n}\left\|x_{n}-p\right\|+\left(1-\beta_{n}\right)\left\|u_{n}-p\right\| \\
& =\beta_{n}\left\|x_{n}-p\right\|+\left(1-\beta_{n}\right)\left\|\Theta^{M} y_{n}-p\right\| \\
& \leq \beta_{n}\left\|x_{n}-p\right\|+\left(1-\beta_{n}\right)\left\|y_{n}-p\right\| \\
& \leq \beta_{n}\left\|x_{n}-p\right\|+\left(1-\beta_{n}\right)\left[\left(1-\alpha_{n}\right)\left\|x_{n}-p\right\|+\alpha_{n}\|p\|\right] \\
& =\left(1-\alpha_{n}\left(1-\beta_{n}\right)\right)\left\|x_{n}-p\right\|+\alpha_{n}\left(1-\beta_{n}\right)\|p\| \\
& \leq \max \left\{\left\|x_{n}-p\right\|,\|p\|\right\} .
\end{aligned}
$$

Hence, by induction, $\left\{x_{n}\right\}$ is bounded and so are $\left\{y_{n}\right\}$ and $\left\{u_{n}\right\}$.

Next, we show that

$$
\lim _{n \rightarrow \infty}\left\|x_{n+1}-x_{n}\right\|=0
$$

Since $u_{n}=\Theta^{M} y_{n}$ and $u_{n+1}=\Theta^{M} y_{n+1}$,

$$
\begin{aligned}
\left\|u_{n+1}-u_{n}\right\| & =\left\|\Theta^{M} y_{n+1}-\Theta^{M} y_{n}\right\| \\
& \leq\left\|y_{n+1}-y_{n}\right\| .
\end{aligned}
$$


Fixed Point Theory and Applications

Set $z_{n}=S_{n} u_{n}, n \in \mathbb{N}$. So, we have from (1.14) and (4.4) that

$$
\begin{aligned}
\left\|z_{n+1}-z_{n}\right\| & =\left\|S_{n+1} u_{n+1}-S_{n} u_{n}\right\| \\
& \leq\left\|S_{n+1} u_{n+1}-S_{n+1} u_{n}\right\|+\left\|S_{n+1} u_{n}-S_{n} u_{n}\right\| \\
& \leq\left\|u_{n+1}-u_{n}\right\|+\left\|S_{n+1} u_{n}-S_{n} u_{n}\right\| \\
& \leq\left\|y_{n+1}-y_{n}\right\|+\left\|S_{n+1} u_{n}-S_{n} u_{n}\right\| \\
& \leq\left\|\left(1-\alpha_{n+1}\right) x_{n+1}-\left(1-\alpha_{n}\right) x_{n}\right\|+\sup _{z \in\left\{u_{n}\right\}}\left\|S_{n+1} z-S_{n} z\right\| \\
& \leq\left\|x_{n+1}-x_{n}\right\|+\alpha_{n+1}\left\|x_{n+1}\right\|+\alpha_{n}\left\|x_{n}\right\|+\sup _{z \in\left\{u_{n}\right\}}\left\|S_{n+1} z-S_{n} z\right\| .
\end{aligned}
$$

Since $\left\{S_{n}\right\}$ satisfies the AKTT-condition and $\lim _{n \rightarrow \infty} \alpha_{n}=0$, it follows that

$$
\limsup _{n \rightarrow \infty}\left(\left\|z_{n+1}-z_{n}\right\|-\left\|x_{n+1}-x_{n}\right\|\right) \leq 0
$$

So, by Lemma 2.2 and (ii), we obtain

$$
\lim _{n \rightarrow \infty}\left\|z_{n}-x_{n}\right\|=0
$$

Hence,

$$
\lim _{n \rightarrow \infty}\left\|x_{n+1}-x_{n}\right\|=\lim _{n \rightarrow \infty}\left(1-\beta_{n}\right)\left\|z_{n}-x_{n}\right\|=0 .
$$

Observe that

$$
\left\|y_{n}-x_{n}\right\|=\left\|P_{C}\left[\left(1-\alpha_{n}\right) x_{n}\right]-P_{C} x_{n}\right\| \leq \alpha_{n}\left\|x_{n}\right\| \longrightarrow 0,
$$

as $n \rightarrow \infty$. Similar to the proof of Theorem 3.1, we obtain for each $p \in F$ that

$$
\begin{gathered}
\left\|u_{n}-p\right\|^{2} \leq\left\|x_{n}-p\right\|^{2}+\alpha_{n} M_{1}^{\prime}+\sum_{i=1}^{M} r_{i}\left(r_{i}-2 \alpha_{i}\right)\left\|A_{i} \Theta^{i-1} y_{n}-A_{i} p\right\|^{2}, \\
\left\|u_{n}-p\right\|^{2} \leq\left\|x_{n}-p\right\|^{2}+\alpha_{n} M_{1}^{\prime}-\sum_{i=1}^{M}\left\|\Theta^{i-1} y_{n}-\Theta^{i} y_{n}\right\|^{2}+M_{2}^{\prime} \sum_{i=1}^{M}\left\|A_{i} \Theta^{i-1} y_{n}-A_{i} p\right\|,
\end{gathered}
$$


for some $M_{1}^{\prime}>0$ and $M_{2}^{\prime}>0$. Then, from (4.10), we have

$$
\begin{aligned}
\left\|x_{n+1}-p\right\|^{2} \leq & \beta_{n}\left\|x_{n}-p\right\|^{2}+\left(1-\beta_{n}\right)\left\|S_{n} u_{n}-p\right\|^{2} \\
\leq & \beta_{n}\left\|x_{n}-p\right\|^{2}+\left(1-\beta_{n}\right)\left\|u_{n}-p\right\|^{2} \\
\leq & \beta_{n}\left\|x_{n}-p\right\|^{2}+\left(1-\beta_{n}\right) \\
& \times\left(\left\|x_{n}-p\right\|^{2}+\alpha_{n} M_{1}^{\prime}+\sum_{i=1}^{M} r_{i}\left(r_{i}-2 \alpha_{i}\right)\left\|A_{i} \Theta^{i-1} y_{n}-A_{i} p\right\|^{2}\right) \\
\leq & \left\|x_{n}-p\right\|^{2}+\alpha_{n} M_{1}^{\prime}+\left(1-\beta_{n}\right) \sum_{i=1}^{M} r_{i}\left(r_{i}-2 \alpha_{i}\right)\left\|A_{i} \Theta^{i-1} y_{n}-A_{i} p\right\|^{2},
\end{aligned}
$$

which implies that

$$
\left(1-\beta_{n}\right) \sum_{i=1}^{M} r_{i}\left(2 \alpha_{i}-r_{i}\right)\left\|A_{i} \Theta^{i-1} y_{n}-A_{i} p\right\|^{2} \leq\left\|x_{n+1}-p\right\|^{2}-\left\|x_{n}-p\right\|^{2}+\alpha_{n} M_{1}^{\prime} .
$$

So, from (4.8), (i), (ii) and $0<r_{k}<2 \alpha_{k}$ for each $k=1,2, \ldots, M$, we have

$$
\lim _{n \rightarrow \infty}\left\|A_{k} \Theta^{k-1} y_{n}-A_{k} p\right\|=0
$$

for each $k \in\{1,2, \ldots, M\}$. Similarly, from (4.11), we have

$$
\begin{aligned}
\left\|x_{n+1}-p\right\|^{2} \leq & \beta_{n}\left\|x_{n}-p\right\|^{2}+\left(1-\beta_{n}\right)\left\|S_{n} u_{n}-p\right\|^{2} \\
\leq & \beta_{n}\left\|x_{n}-p\right\|^{2}+\left(1-\beta_{n}\right)\left\|u_{n}-p\right\|^{2} \\
\leq & \beta_{n}\left\|x_{n}-p\right\|^{2}+\left(1-\beta_{n}\right) \\
& \times\left(\left\|x_{n}-p\right\|^{2}+\alpha_{n} M_{1}^{\prime}-\sum_{i=1}^{M}\left\|\Theta^{i-1} y_{n}-\Theta^{i} y_{n}\right\|^{2}+M_{2}^{\prime} \sum_{i=1}^{M}\left\|A_{i} \Theta^{i-1} y_{n}-A_{i} p\right\|\right) \\
\leq & \left\|x_{n}-p\right\|^{2}+\alpha_{n} M_{1}^{\prime}-\left(1-\beta_{n}\right) \sum_{i=1}^{M}\left\|\Theta^{i-1} y_{n}-\Theta^{i} y_{n}\right\|^{2}+M_{2}^{\prime} \sum_{i=1}^{M}\left\|A_{i} \Theta^{i-1} y_{n}-A_{i} p\right\| .
\end{aligned}
$$

This implies that

$$
\begin{aligned}
& \left(1-\beta_{n}\right) \sum_{i=1}^{M}\left\|\Theta^{i-1} y_{n}-\Theta^{i} y_{n}\right\|^{2} \\
& \quad \leq\left\|x_{n}-p\right\|^{2}-\left\|x_{n+1}-p\right\|^{2}+\alpha_{n} M_{1}^{\prime}+M_{2}^{\prime} \sum_{i=1}^{M}\left\|A_{i} \Theta^{i-1} y_{n}-A_{i} p\right\| .
\end{aligned}
$$


From (i), (ii), (4.8), and (4.14), it follows that

$$
\lim _{n \rightarrow \infty}\left\|\Theta^{k-1} y_{n}-\Theta^{k} y_{n}\right\|=0,
$$

for each $k \in\{1,2, \ldots, M\}$.

Next, we show that

$$
\lim _{n \rightarrow \infty}\left\|x_{n}-S x_{n}\right\|=0
$$

Observing

$$
\begin{aligned}
\left\|u_{n}-y_{n}\right\| & =\left\|\Theta^{M} y_{n}-y_{n}\right\| \\
& \leq\left\|\Theta^{M} y_{n}-\Theta^{M-1} y_{n}\right\|+\left\|\Theta^{M-1} y_{n}-\Theta^{M-2} y_{n}\right\|+\cdots+\left\|\Theta^{1} y_{n}-y_{n}\right\|,
\end{aligned}
$$

it follows, by (4.17), that

$$
\lim _{n \rightarrow \infty}\left\|u_{n}-y_{n}\right\|=0
$$

From (4.9) and (4.20), we have

$$
\lim _{n \rightarrow \infty}\left\|u_{n}-x_{n}\right\|=0
$$

We see that

$$
\begin{aligned}
\left\|x_{n}-S x_{n}\right\| & \leq\left\|x_{n}-S_{n} u_{n}\right\|+\left\|S_{n} u_{n}-S_{n} x_{n}\right\|+\left\|S_{n} x_{n}-S x_{n}\right\| \\
& \leq\left\|x_{n}-S_{n} u_{n}\right\|+\left\|u_{n}-x_{n}\right\|+\sup _{z \in\left\{x_{n}\right\}}\left\|S_{n} z-S z\right\| .
\end{aligned}
$$

So, by (4.7), (4.21), and Lemma 2.5, we have

$$
\lim _{n \rightarrow \infty}\left\|x_{n}-S x_{n}\right\|=0
$$

Let the net $\left\{x_{t}\right\}$ be defined by (3.3). By Theorem 3.1, we have $x_{t} \rightarrow x^{*} \in F$ as $t \rightarrow 0$. Moreover, by proving in the same manner as in Theorem 3.2 of [25], we can show that

$$
\limsup _{n \rightarrow \infty}\left\langle x^{*}, x^{*}-x_{n}\right\rangle \leq 0
$$


Finally, we show that $x_{n} \rightarrow x^{*} \in F$ as $n \rightarrow \infty$. From (1.14), we have

$$
\begin{aligned}
\left\|x_{n+1}-x^{*}\right\|^{2} \leq & \beta_{n}\left\|x_{n}-x^{*}\right\|^{2}+\left(1-\beta_{n}\right)\left\|S_{n} u_{n}-x^{*}\right\|^{2} \\
\leq & \beta_{n}\left\|x_{n}-x^{*}\right\|^{2}+\left(1-\beta_{n}\right)\left\|u_{n}-x^{*}\right\|^{2} \\
\leq & \beta_{n}\left\|x_{n}-x^{*}\right\|^{2}+\left(1-\beta_{n}\right)\left\|y_{n}-x^{*}\right\|^{2} \\
\leq & \beta_{n}\left\|x_{n}-x^{*}\right\|^{2}+\left(1-\beta_{n}\right)\left\|\left(1-\alpha_{n}\right)\left(x_{n}-x^{*}\right)-\alpha_{n} x^{*}\right\|^{2} \\
\leq & \beta_{n}\left\|x_{n}-x^{*}\right\|^{2}+\left(1-\beta_{n}\right) \\
& \times\left(\left(1-\alpha_{n}\right)\left\|x_{n}-x^{*}\right\|^{2}-2 \alpha_{n}\left(1-\alpha_{n}\right)\left\langle x^{*}, x_{n}-x^{*}\right\rangle+\alpha_{n}^{2}\left\|x^{*}\right\|^{2}\right) \\
= & \left(1-\alpha_{n}\left(1-\beta_{n}\right)\right)\left\|x_{n}-x^{*}\right\|^{2} \\
& +\alpha_{n}\left(1-\beta_{n}\right)\left(2\left(1-\alpha_{n}\right)\left\langle x^{*}, x^{*}-x_{n}\right\rangle+\alpha_{n}\left\|x^{*}\right\|^{2}\right) .
\end{aligned}
$$

By (i) and (4.24), it follows from Lemma 2.3 that $x_{n} \rightarrow x^{*} \in F$. This completes the proof.

As a direct consequence of Lemmas 2.6 and 2.7 and Theorem 4.1, we obtain the following result.

Theorem 4.2. Let $C$ be a nonempty, closed, and convex subset of a real Hilbert space $H$. Let $\left\{f_{k}\right\}_{k=1}^{M}$ : $C \times C \rightarrow \mathbb{R}$ be a family of bifunctions, let $\left\{A_{k}\right\}_{k=1}^{M}: C \rightarrow H$ be a family of $\alpha_{k}$-inverse-strongly monotone mappings, and let $\left\{S_{i}\right\}_{i=1}^{\infty}$ be a sequence of $\kappa_{i}$-strict pseudocontractions of $C$ into itself such that $F:=\left(\bigcap_{k=1}^{M} \operatorname{GEP}\left(f_{k}, A_{k}\right)\right) \cap\left(\bigcap_{i=1}^{\infty} F\left(S_{i}\right)\right) \neq \emptyset$ and $\sup \left\{\kappa_{i}: i \in \mathbb{N}\right\}=\kappa>0$. Assume that $\gamma \in(\kappa, 1)$ and $r_{k} \in\left(0,2 \alpha_{k}\right)$ for each $k \in\{1,2, \ldots, M\}$. Define the sequence $\left\{x_{n}\right\}$ by $x_{1} \in C$ and

$$
\begin{gathered}
y_{n}=P_{C}\left[\left(1-\alpha_{n}\right) x_{n}\right], \\
u_{n}=T_{r_{M}}^{f_{M}, A_{M}} T_{r_{M-1}}^{f_{M-1}, A_{M-1}} \cdots T_{r_{2}}^{f_{2}, A_{2}} T_{r_{1}}^{f_{1}, A_{1}} y_{n} \\
x_{n+1}=\beta_{n} x_{n}+\left(1-\beta_{n}\right)\left[\gamma u_{n}+(1-\gamma) \sum_{i=1}^{n} \mu_{n}^{i} S_{i} u_{n}\right], \quad n \geq 1,
\end{gathered}
$$

where $\left\{\alpha_{n}\right\}_{n=1}^{\infty}$ and $\left\{\beta_{n}\right\}_{n=1}^{\infty}$ are real sequences in $(0,1)$ which satisfy (i)-(ii) of Theorem 4.1 and $\left\{\mu_{n}^{i}\right\}$ is a real sequence which satisfies (i)-(iii) of Lemma 2.7. Then, $\left\{x_{n}\right\}$ converges strongly to an element in F.

Remark 4.3. Theorems 4.1 and 4.2 extend the main results in [25] from a nonexpansive mapping to an infinite family of strict pseudocontractions and a system of generalized equilibrium problems.

Remark 4.4. If we take $A_{k} \equiv 0$ and $f_{k} \equiv 0$ for each $k=1,2, \ldots, M$, then Theorems 3.1, 4.1, and 4.2 can be applied to a system of equilibrium problems and to a system of variational inequality problems, respectively. 
Remark 4.5. Let $S_{1}, S_{2}, \ldots$ be an infinite family of nonexpansive mappings of $C$ into itself, and let $\xi_{1}, \xi_{2}, \ldots$ be real numbers such that $0<\xi_{i}<1$ for all $i \in \mathbb{N}$. Moreover, let $W_{n}$ and $W$ be the $W$-mappings [35] generated by $S_{1}, S_{2}, \ldots, S_{n}$ and $\xi_{1}, \xi_{2}, \ldots, \xi_{n}$ and $S_{1}, S_{2}, \ldots$ and $\xi_{1}, \xi_{2}, \ldots$. Then, we know from $[7,35]$ that $\left(\left\{W_{n}\right\}, W\right)$ satisfies the AKTT-condition. Therefore, in Theorem 4.1, the mapping $T_{n}$ can be also replaced by $W_{n}$.

\section{Acknowledgments}

The authors would like to thank the referees for valuable suggestions. This research is supported by the Centre of Excellence in Mathematics, the Commission on Higher Education, and the Thailand Research Fund. The first author is supported by the Royal Golden Jubilee Grant no. PHD/0261/2551 and by the Graduate School, Chiang Mai University, Thailand.

\section{References}

[1] E. Blum and W. Oettli, "From optimization and variational inequalities to equilibrium problems," The Mathematics Student, vol. 63, no. 1-4, pp. 123-145, 1994.

[2] A. Moudafi and M. Théra, "Proximal and dynamical approaches to equilibrium problems," in Ill-Posed Variational Problems and Regularization Techniques, vol. 477 of Lecture Notes in Economics and Mathematical Systems, pp. 187-201, Springer, Berlin, Germany, 1999.

[3] V. Colao, G. L. Acedo, and G. Marino, "An implicit method for finding common solutions of variational inequalities and systems of equilibrium problems and fixed points of infinite family of nonexpansive mappings," Nonlinear Analysis: Theory, Methods E Applications, vol. 71, no. 7-8, pp. 27082715, 2009.

[4] P. Cholamjiak and S. Suantai, "Convergence analysis for a system of equilibrium problems and a countable family of relatively quasi-nonexpansive mappings in Banach spaces," Abstract and Applied Analysis, vol. 2010, Article ID 141376, 17 pages, 2010.

[5] C. Jaiboon, "The hybrid steepest descent method for addressing fixed point problems and system of equilibrium problems," Thai Journal of Mathematics, vol. 8, pp. 275-292, 2010.

[6] T. Jitpeera and P. Kumam, "An extragradient type method for a system of equilibrium problems, variational inequality problems and fixed points of finitely many nonexpansive mappings," Journal of Nonlinear Analysis and Optimization, vol. 1, pp. 71-91, 2010.

[7] J.-W. Peng and J.-C. Yao, "A viscosity approximation scheme for system of equilibrium problems, nonexpansive mappings and monotone mappings," Nonlinear Analysis: Theory, Methods $\mathcal{E}$ Applications, vol. 71, no. 12, pp. 6001-6010, 2009.

[8] G. Marino and H.-K. Xu, "Weak and strong convergence theorems for strict pseudo-contractions in Hilbert spaces," Journal of Mathematical Analysis and Applications, vol. 329, no. 1, pp. 336-346, 2007.

[9] W. R. Mann, "Mean value methods in iteration," Proceedings of the American Mathematical Society, vol. 4, pp. 506-510, 1953.

[10] S. Reich, "Weak convergence theorems for nonexpansive mappings in Banach spaces," Journal of Mathematical Analysis and Applications, vol. 67, no. 2, pp. 274-276, 1979.

[11] F. E. Browder and W. V. Petryshyn, "Construction of fixed points of nonlinear mappings in Hilbert space," Journal of Mathematical Analysis and Applications, vol. 20, pp. 197-228, 1967.

[12] H. Zhou, "Convergence theorems of fixed points for Lipschitz pseudo-contractions in Hilbert spaces," Journal of Mathematical Analysis and Applications, vol. 343, no. 1, pp. 546-556, 2008.

[13] G. L. Acedo and H. K. Xu, "Iterative methods for strict pseudo-contractions in Hilbert spaces," Nonlinear Analysis: Theory, Methods \& Applications, vol. 67, no. 7, pp. 2258-2271, 2007.

[14] L. C. Ceng, D. S. Shyu, and J. C. Yao, "Relaxed composite implicit iteration process for common fixed points of a finite family of strictly pseudocontractive mappings," Fixed Point Theory and Applications, vol. 2009, Article ID 402602, 16 pages, 2009.

[15] L.-C. Ceng, A. Petruşel, and J.-C. Yao, "Strong convergence of modified implicit iterative algorithms with perturbed mappings for continuous pseudocontractive mappings," Applied Mathematics and Computation, vol. 209, no. 2, pp. 162-176, 2009. 
[16] L.-C. Ceng, S. Al-Homidan, Q. H. Ansari, and J.-C. Yao, “An iterative scheme for equilibrium problems and fixed point problems of strict pseudo-contraction mappings," Journal of Computational and Applied Mathematics, vol. 223, no. 2, pp. 967-974, 2009.

[17] P. Cholamjiak and S. Suantai, "Weak convergence theorems for a countable family of strict pseudocontractions in banach spaces," Fixed Point Theory and Applications, vol. 2010, Article ID 632137, 16 pages, 2010.

[18] J.-W. Peng and J.-C. Yao, "Ishikawa iterative algorithms for a generalized equilibrium problem and fixed point problems of a pseudo-contraction mapping," Journal of Global Optimization, vol. 46, no. 3, pp. 331-345, 2010.

[19] Y. Zhang and Y. Guo, "Weak convergence theorems of three iterative methods for strictly pseudocontractive mappings of Browder-Petryshyn type," Fixed Point Theory and Applications, vol. 2008, Article ID 672301, 13 pages, 2008.

[20] H. Zhang and Y. Su, "Convergence theorems for strict pseudo-contractions in $q$-uniformly smooth Banach spaces," Nonlinear Analysis: Theory, Methods E Applications, vol. 71, no. 10, pp. 4572-4580, 2009.

[21] H. Zhou, "Convergence theorems for $\lambda$-strict pseudo-contractions in 2-uniformly smooth Banach spaces," Nonlinear Analysis: Theory, Methods E Applications, vol. 69, no. 9, pp. 3160-3173, 2008.

[22] H.Y. Zhou, "Convergence theorems for $\lambda$-strict pseudo-contractions in $q$-uniformly smooth Banach spaces," Acta Mathematica Sinica, vol. 26, no. 4, pp. 743-758, 2010.

[23] A. Moudafi, "Weak convergence theorems for nonexpansive mappings and equilibrium problems," Journal of Nonlinear and Convex Analysis, vol. 9, no. 1, pp. 37-43, 2008.

[24] S. Takahashi and W. Takahashi, "Strong convergence theorem for a generalized equilibrium problem and a nonexpansive mapping in a Hilbert space," Nonlinear Analysis: Theory, Methods E Applications, vol. 69, no. 3, pp. 1025-1033, 2008.

[25] Y. Yao, Y. C. Liou, and G. Marino, "Strong convergence of two iterative algorithms for nonexpansive mappings in Hilbert spaces," Fixed Point Theory and Applications, vol. 2009, Article ID 279058, 7 pages, 2009.

[26] P. L. Combettes and S. A. Hirstoaga, "Equilibrium programming in Hilbert spaces," Journal of Nonlinear and Convex Analysis, vol. 6, no. 1, pp. 117-136, 2005.

[27] F. E. Browder, "Nonexpansive nonlinear operators in a Banach space," Proceedings of the National Academy of Sciences of the United States of America, vol. 54, pp. 1041-1044, 1965.

[28] K. Goebel and W. A. Kirk, Topics in Metric Fixed Point Theory, vol. 28 of Cambridge Studies in Advanced Mathematics, Cambridge University Press, Cambridge, UK, 1990.

[29] T. Suzuki, "Strong convergence of Krasnoselskii and Mann's type sequences for one-parameter nonexpansive semigroups without Bochner integrals," Journal of Mathematical Analysis and Applications, vol. 305, no. 1, pp. 227-239, 2005.

[30] H.-K. Xu, "Iterative algorithms for nonlinear operators," Journal of the London Mathematical Society, vol. 66, no. 1, pp. 240-256, 2002.

[31] N. Nadezhkina and W. Takahashi, "Weak convergence theorem by an extragradient method for nonexpansive mappings and monotone mappings," Journal of Optimization Theory and Applications, vol. 128, no. 1, pp. 191-201, 2006.

[32] K. Aoyama, Y. Kimura, W. Takahashi, and M. Toyoda, "Approximation of common fixed points of a countable family of nonexpansive mappings in a Banach space," Nonlinear Analysis: Theory, Methods $\mathcal{E}$ Applications, vol. 67, no. 8, pp. 2350-2360, 2007.

[33] D. Boonchari and S. Saejung, "Weak and strong convergence theorems of an implicit iteration for a countable family of continuous pseudocontractive mappings," Journal of Computational and Applied Mathematics, vol. 233, no. 4, pp. 1108-1116, 2009.

[34] D. Boonchari and S. Saejung, "Construction of common fixed points of a countable family of $\lambda$-demicontractive mappings in arbitrary Banach spaces," Applied Mathematics and Computation, vol. 216, no. 1, pp. 173-178, 2010.

[35] K. Shimoji and W. Takahashi, "Strong convergence to common fixed points of infinite nonexpansive mappings and applications," Taiwanese Journal of Mathematics, vol. 5, no. 2, pp. 387-404, 2001. 